\title{
Application of a yeast-based assay protocol developed to monitor total oestrogenic activity induced by $17 \beta$-oestradiol in activated sludge supernatants from batch experiments
}

\author{
E Wozei* and SW Hermanowicz \\ Department of Civil and Environmental Engineering, 629 Davis Hall, University of California at Berkeley, Berkeley, CA, 94720
}

\begin{abstract}
Batch experiments were carried out with activated sludge from laboratory reactors and a full-scale treatment plant spiked with $17 \beta$-oestradiol (E2). An oestrogen-sensitive yeast-based assay protocol, described in detail in a related publication, was used to measure reduction of E2-induced total oestrogenic activity from the sludge supernatant over a $15 \mathrm{~d}$ period after which the sludge was re-spiked to check for possible enhancement of reduction by pre-exposed sludge during an additional $15 \mathrm{~d}$ period. The reduction was generally improved by increasing sludge solids concentrations and by continuous mixing. For a $100 \mathrm{ngE} 2 / \ell$ spike there was $>40 \%$ reduction of oestrogenic activity within $15 \mathrm{~d}$, which improved to $>70 \%$ by pre-exposing the sludge. The oestrogenic activity produced by a dose of $100 \mu \mathrm{gE} 2 / \ell$ was readily removed by most sludges within $15 \mathrm{~d}$. However, re-spiking the activated sludge with the same E2 concentration caused some sludges to lose reduction capacity.
\end{abstract}

Keywords: activated sludge, $17 \beta$-oestradiol, oestrogen, oestrogen receptor, oestrogenic activity, suspended solids, wastewater treatment, yeast assay

\section{Introduction}

Environmental oestrogens are environmental contaminants that can mimic the biological activities of the female hormone oestrogen in the endocrine system, i.e. they act as endocrine disrupters. Several substances are reported to have oestrogen-like activity. These include steroid hormones, synthetic oestrogens (xeno-oestrogens), environmental pollutants and phyto-oestrogens (plant oestrogens) (Arnold et al., 1996; Routledge and Sumpter, 1996; Coldham et al., 1997; Hu et al., 2000; Körner et al., 2000).

Some of these environmental oestrogens share physical and chemical characteristics which make them able to behave like, or induce a hormonal response similar to $17 \beta$-oestradiol (E2). These characteristics include their chemical structure, water solubility, and affinity for organic matter. Others do not share any structural resemblance, but can still induce a similar biological response (Zacharewski, 1997). This paper limits the definition of environmental oestrogens to those substances that can bind to and activate the oestrogen receptor (ER), and will refer to them as oestrogenic compounds or oestrogens. Primary emphasis is placed on the steroid oestrogen E2 found in domestic wastewater treatment.

\section{Estrogens in wastewater treatment plants}

Where there is a conventional wastewater collection and treatment system, some oestrogens will eventually pass through a wastewater treatment plant before being discharged to the

\footnotetext{
* To whom all correspondence should be addressed.

Current address: Lawrence Berkeley National Laboratory, Mail Stop 70A-3317, 1 Cyclotron Road, Berkeley, CA, 94720

일 1510486 7094; fax: 15104867152 ;

e-mail: EWozei@LBL.gov

Received 21 June 2005; accepted in revised form 11 April 2006.
}

environment (Ternes et al., 1999b). The oestrogenic input to rivers by treatment plant effluent can be quite significant. Körner et al. (2000) found E2-equivalent concentrations of between 2.5 and $25 \mathrm{ng} / \ell$ in effluent from municipal wastewater plants in southern Germany. Effluents may have up to $50 \mathrm{ng} / \ell$ of E2 alone (Desbrow et al., 1998; Belfroid et al., 1999; Layton et al., 2000) and total oestrogenic activity up to 150 ngE2-equivalent/ $\ell$ (Körner et al., 2000; Tilton et al., 2002; Pawlowski et al., 2003; Pawlowski et al., 2004). Typical effluents have less than $20 \mathrm{ngE} 2 / \ell$. While many receiving water studies have been carried out on river and lake water, there is now concern that ocean effluent outfalls may be a source of oestrogens to coastal marine environments (Atkinson et al., 2003). Solids disposal may also be a source of oestrogen to the environment from treatment plants as the hydrophobic oestrogens are expected to associate with the organic solids in treatment processes (Johnson et al., 1999). Sludge $\mathrm{E} 2$ concentrations of up to $4.3 \mathrm{ng} / \ell$ were measured by Murk et al. (2002).

\section{Oestrogen reduction and organic solids in wastewa- ter treatment}

Steroid oestrogens have low water solubility - generally in the low $\mathrm{mg} / \ell$ range (Tabak et al., 1981; Merck Index, 1996) - but at typical $\mathrm{ng} / \ell$ concentrations found in wastewaters they will be in solution in samples to be analysed. However, some quantities of oestrogens will also be associated with solids and must be accounted for. Domestic wastewater typically has between 80 to $290 \mathrm{mg} / \ell$ of total organic carbon (TOC) and some treatment processes like the activated sludge (AS) system have up to $10 \mathrm{~g} / \ell$ of organic solids (Tchobanoglous et al., 1991). Steroid oestrogens have relatively high $\mathrm{K}_{\text {ow }}$ values with calculated and experimental values of $\log \mathrm{K}_{\text {ow }}$ reported in a range of 2.45 to 4.15 (Hansch et al., 1995; Hu et al., 2000; Lai et al., 2000). Their implied hydrophobicity means that some of the dissolved oestrogenic compounds may partition out of the water phase onto the 
organic solids in the treatment plant processes, a phenomenon which could be exploited for reduction of oestrogens in the treatment plant.

Huang and Sedlak (2001) estimated that with an octanolwater partition coefficient $(\mathrm{K}$ ) of approximately 15000 (corresponding to $\log \mathrm{K}_{\mathrm{ow}}=4.2$ ), up to $70 \%$ of $\mathrm{E} 2$ may be associated with organic solids for an AS system with a volatile suspended solids (VSS) concentration of $2 \mathrm{~g} / \ell$. Holbrook et al. (2003a; 2004) suggested that a substantial portion of the aqueous E2 and $17 \alpha$-ethinyloestradiol (EE2) concentrations (up to $60 \%$ ) may be associated with colloidal organic material, and that colloidal organic carbon may play a role in the fate and transport of E2 and EE2 in the activated sludge treatment process. This may be reflected in the removals in batch experiments with AS of up to $100 \%$ (Ternes et al., 1999a). Since other estrogenic compounds have similar or higher partition coefficients, it is possible that the reduction of total estrogenic activity with AS is at least $70 \%$ since AS systems are typically operated with mixed liquor VSS of $2 \mathrm{~g} / \ell$ or more. Also, from reported removals, it appears that lower E2 concentrations are removed more readily, i.e. in shorter time periods (Ternes et al., 1999a; Ternes et al., 1999b; Murk et al., 2002; Onda et al., 2003). This could mean that removal of the $n g / \ell$ levels of steroid oestrogens entering treatment plants with AS systems is feasible during typical AS system hydraulic detention times of 4 to $8 \mathrm{~h}$ (Tchobanoglous et al., 1991). However, since E2 is metabolised to estrone (E1) during the treatment process, measurement of both substances - and less potent metabolites - is required to quantify overall reduction in oestrogenic activity. Spiked experiments with river water suggest that complete reduction of oestrogenic activity would take at least as long as the removal of E1 (Jurgens et al., 2002).

Some studies, however, have disputed the importance of organic solids in oestrogen and oestrogenic activity reduction. For example, a study by Fürhacker et al. (1999) using ${ }^{3} \mathrm{H}$ radiolabelled E2 found that for raw wastewater with $128 \mathrm{mg} / \ell$ suspended solids and $101 \mathrm{mg} / \ell$ total organic carbon content, $86 \%$ of the radioactivity remained in the liquid phase after filtration. This was taken to mean that very little of the oestrogen would associate with solids. Körner et al. (2000) estimated that of the $90 \%$ reduction of oestrogenic activity in a German wastewater plant with an AS system (effluent $\mathrm{BOD}_{5}=1$ to $12 \mathrm{mg} / \ell$ ), only about $3 \%$ could be accounted for in the dried sludge samples. It was concluded that the rest was removed by biodegradation. However, calculations by Johnson et al. (1999) estimated that after $22 \mathrm{~h}$ equilibration with organic flocs with an equilibrium distribution coefficient of $3360 \mathrm{l} / \mathrm{kg}$, at least $92 \%$ of influent E2 is expected to adsorb even without degradation. And a study by Lee and Liu (2002) found that in aerobic batch experiments, while activated sludge supernatant (total suspended solids (TSS) concentration $<1 \mathrm{gTSS} / \ell$ ) could remove over $80 \%$ of a spiked dose of $200 \mu \mathrm{gE} 2 / \ell$ by almost quantitative conversion to its metabolite E1 within $24 \mathrm{~h}$, the degradation of E1 was much slower requiring $14 \mathrm{~d}$ for $>90 \%$ removal. This would mean that although the primary source of oestrogenic activity is rapidly removed, total oestrogenic activity (measured by bioassays like the yeast assay) would require over 2 weeks for complete reduction

In another study, Jensen and Schäfer (2001) found that increasing activated sludge concentration from about 2 to $8 \mathrm{gTSS} / \ell$ did improve E1 reduction over $24 \mathrm{~h}$ of contact, although the percentage reduction remained the same for concentrations ranging from 1 to $500 \mathrm{ngEl} / \ell$. At $8 \mathrm{gTSS} / \ell$, the maximum reduction was about $30 \%$ at all concentrations. Slow reduction of E1 is expected; however, Jensen and Schäfer (2001) attributed all the removal to adsorption of solids although they did not report sludge sterility, which would mean that some microbial reduction cannot be entirely ruled out.

\section{Metabolism of oestrogens in wastewater treatment}

Layton et al. (2000) found that for the treatment plants they sampled the micro-organisms from the municipal treatment plants adapted and became more efficient in the removal of oestrogen than those from industrial treatment plants. Yu et al. (2005) used a quantitative molecular fingerprinting assay to show that after five successive weekly sub-culturing enrichments, oestrogen-degrading consortia of micro-organisms enriched from activated sludge showed enhanced degradation ability with a reduction in the time required for complete degradation of $1 \mathrm{mg} / \ell$ of EE2, E1 and E2 from 7 to $3 \mathrm{~d}$, with changes in microbial diversity and abundance. This confirms the findings of an early study by Tabak and Bunch (1970) which showed that 'subculture enrichment ... had a significant effect in enhancing the selection of micro-organisms in the total microbial population capable of cleaving and biodegrading the steroid molecule'. This could mean that wastewater management methods that actively encourage oestrogen removal could develop biological solids populations, which have good removal efficiencies, by selective sub-culturing or solids recycling.

If AS micro-organisms are able to metabolise oestrogens during the treatment process retention time, then microbial metabolism may be an additional important removal mechanism. A better understanding of how the micro-organisms already present in wastewater treatment process reactors metabolise oestrogen may allow process engineers to optimise the system for oestrogen removal. Wastewater micro-organisms such as Escherichia coli $(E$. coli) bacteria have existing metabolic pathways and enzymes that they may be able to use in oestrogen metabolism and removal (Kyoto Encyclopedia of Genes and Genomes). The $\beta$-glucuronidase and arylsulphatase enzymes produced by the E. coli present in wastewater may be responsible for de-conjugation of conjugated oestrogens in the sewers before the water reaches the treatment plant (Ralovich et al., 1991; Kertesz, 1999; D'Ascenzo et al., 2003). Batch studies on male and female urine sample extracts showed that $E$. coli can convert oestrogenic metabolites in urine to biologically active oestrogens (Legler et al., 2002).

In this study, oestrogenic activity reduction was expected to be both due to adsorption of the hydrophobic oestrogens to organic solids, and the microbial reduction by live microorganisms that make up AS. The effects of continuous mixing and absence of AS solids were investigated by including suitable controls. Re-spiking of sludges which had been pre-exposed to E2 was also carried out to determine whether there was any benefit in E2-induced oestrogenic activity reduction by acclimating activated sludges prior to their use in treatment.

\section{Study objective}

The objective of the study was to determine and better understand the role of activated sludge solids, and the trends in removal of E2-induced oestrogenic activity with activated sludge using a promising yeast-based assay protocol developed previously. The yeast-based assay allows rapid determination of the relative oestrogenic activity of the supernatant of E2-spiked AS samples without the requirement of sample extraction. 


\section{Materials and methods}

\section{Yeast strains and culture technique}

Parent strain RMY326 and its recombinant construct RMY/ERERE of the budding yeast Saccharomyces cerevisiae were a free gift from Dr Didier Picard (University of Geneva, Switzerland). The parent strain RMY326 (MATa his3 leu2-3, 112 trp1-1 ura352) was transformed with $\mathrm{pG} / \mathrm{ER}(\mathrm{G})$ a plasmid encoding the wild-type human oestrogen receptor (hER), and pUC $\triangle$ SS-ERE a reporter plasmid containing an oestrogen response element to give the construct RMY/ER-ERE (his3 leu2-3, 112 trp1-1 ura352 / hER-TRP1-2 $\mu$ - [pG/ER(G)], ERE-CYC1-LacZ-URA3- $2 \mu$ [pUCASS-ERE], HIS3-CEN/ARS [pRS423]). The construct expresses the wild-type human oestrogen receptor $\alpha(\mathrm{hER} \alpha)$ and contains an ER reporter gene (Liu and Picard, 1998; Picard, 2001).

The construct was selectively cultured using a selective medium (SM) without the amino acids histidine (His), methionine (Met) and tryptophan (Trp). Selective media broth/agar (Klein et al., 1994) contained: $20 \mathrm{~g} / \ell$ glucose/dextrose (Fisher Scientific, USA), $6.7 \mathrm{~g} / \ell$ yeast nitrogen base without amino acids (Difco, USA), $0.032 \mathrm{~g} / \ell$ adenine sulphate (ICN Biomedical, USA), $5 \mathrm{~g} / \ell$ casamino acids (Fisher Scientific, USA), $2 \%$ bacto-agar [for agar plate] (Fisher Scientific, USA) in nanopure water (Barnstead nanopure system, USA). The medium was filter sterilised using an $0.2 \mu \mathrm{m}$ pore-size syringe filter paper (Cole-Parmer, USA). The medium was prepared and stored under refrigeration as a $10 \mathrm{X}$ solution and diluted as necessary using nanopure water.

Selectivity of the medium was tested by attempting to grow the parent strain RMY326 on selective medium. No colonies were observed in 2 separate trials on SM agar plates and 1 trial in SM broth over $7 \mathrm{~d}$ periods. However, the parent strain was able to grow on general media agar containing: $10 \mathrm{~g} / \ell$ yeast extract (Fisher Scientific, USA), $10 \mathrm{~g} / \ell$ dextrose (Fisher Scientific, USA), and $15 \mathrm{~g} / \ell$ bacto-agar in distilled water (Fisher Scientific, USA) and YPD (yeast peptone dextrose) broth containing: $10 \mathrm{~g} / \ell$ yeast extract (Fisher Scientific, USA), $20 \mathrm{~g} / \ell$ bacto-peptone (Difco, USA), and $20 \mathrm{~g} / \ell$ dextrose (Fisher Scientific, USA) in nanopure water - confirming that in this study, the selective medium only allows growth of the yeast construct.

The CYC1 promoter reduces the chance of oestrogen-independent gene transcription (Joyeux et al., 1997), but a medium blank was included in all assays since some researchers have found media (Liu and Picard, 1998) and substrate (Vanderperren et al., 2001) oestrogenic effects in some assays.

\section{$17 \beta$-estradiol (E2) standards preparation}

A $10 \mathrm{mM}\left(10^{-2} \mathrm{M}\right)$ solution of $17 \beta$-estradiol (E2) standard (Calbiochem, USA) was made by dissolving $136.2 \mathrm{mg}$ of $\mathrm{E} 2$ in $50 \mathrm{~m} \ell$ of absolute denatured ethanol (Fisher Scientific, USA). A range of stock standards from $10^{-3} \mathrm{M}$ to $10^{-11} \mathrm{M}$ was then made up by serial dilution of the $10^{-2} \mathrm{M}$ stock standard (1:10) in absolute ethanol. Working standards ranging from $10^{-4} \mathrm{M}$ to $10^{-13} \mathrm{M}$ were made by diluting each stock standard 1:100 in filter-sterilised AS feed solution.

\section{Assay protocol outline}

Briefly, $250 \mu \ell$ of working standard was incubated with $200 \mu \ell$ of yeast culture and $750 \mu \ell$ of SM for $20 \mathrm{~h}$ at $30^{\circ} \mathrm{C}$. The yeast cells were collected by centrifugation, the supernatant discarded, and the cells re-suspended in $2 \mathrm{~m} \ell \mathrm{Z}$-buffer and the optical density read at $630 \mathrm{~nm} .100 \mu \ell$ of cell suspension was added to a reaction tube containing excess ortho-nitrophenyl- $\beta$-D-galactopyranoside (ONPG) chromogenic substrate, SDS and chloroform at $30^{\circ} \mathrm{C}$. The mixture was incubated for $6 \mathrm{~min}$ and the reaction stopped with $1 \mathrm{~m} \ell$ of $1 \mathrm{M}$ sodium carbonate $\left(\mathrm{Na}_{2} \mathrm{CO}_{3}\right)$. The reaction mixture was centrifuged to separate cell debris, and the absorbance of the supernatant containing yellow $o$-nitrophenol $(\mathrm{ONP})$ product was read at $420 \mathrm{~nm}$. All optical density absorbance readings were taken using a spectrophotometer with a $1 \mathrm{~cm}$ path length quartz cuvette (Perkin Elmer UV/VIS Spectrometer Lambda 10, USA).

AS supernatant samples were assayed in the same way as the working standards, with $250 \mu \ell$ of sample replacing the $250 \mu \ell$ of standard in the assay. Each group of samples was assayed with a set of standards dissolved in the same AS feed used to maintain the batch AS experiments, and with the same yeast culture.

\section{Calculation of E2-induced oestrogenic activity}

Absorbance readings from the samples were converted into enzyme activities and then E2-equivalent concentrations as follows (Hermanowicz and Wozei, 2002). $\beta$-galactosidase activity is given by:

$$
\text { activity }=\frac{A_{420} V_{T O T}}{\varepsilon L T V_{Y W S} A_{630}} \quad[\mu \mathrm{mol} / \mathrm{ml} \text {-min }]
$$

where for each reaction tube:

$A_{420}=$ absorbance of ONP product measured at $420 \mathrm{~nm}$

$A_{630}=$ absorbance (optical density) of yeast cell suspension measured at $630 \mathrm{~nm}$

$V_{\text {TOT }}=$ volume of stopped reaction mixture $[\mathrm{m} \ell]$

$V_{Y W S}=$ volume of yeast cell suspension used [m $\left.\ell\right]$

$\varepsilon=$ molar extinction coefficient $[4.5 \mathrm{~m} \ell / \mu \mathrm{mol}-\mathrm{cm}$ (Becerra et al., 2001)]

$L \quad=$ cuvette path length $[1 \mathrm{~cm}]$

$T=$ time between addition of yeast culture to ONPG and stopping with $1 \mathrm{M} \mathrm{Na}_{2} \mathrm{CO}_{3}[6 \mathrm{~min}]$

The activity induced by each standard was normalised by the maximum induced activity to give a ratio termed the activity ratio (AR) which was defined as the ratio of the measured activity in a given sample to the maximum activity measured in assay of standards with the same yeast culture, i.e.:

$\mathrm{AR}=[$ measured activity in given sample $]:[$ maximum activity measured in assay of standards with the same yeast culture]

The normalised activities from an assay of the standards were plotted against E2 concentration to give a standard curve. Experimental samples were assayed in the same way as the standards and normalised to obtain the sample AR. Sample E2-equivalent concentrations could then be estimated by point-by-point interpolation on the standard curve. Fresh standards were prepared for each fresh AS feed batch and a set of standards was assayed with each experimental sample set.

\section{Activated sludge (AS) sources}

The sludge used for the experiments was obtained from laboratory bench-scale AS reactors (December 2001 - September 2002) at the University of California, Berkeley (California, 
USA). Sludge samples from laboratory bench-scale sequencing batch reactors (SBRs) (SBR \#1, July 2002) and (SBR \#2, December 2001) were also obtained for laboratory-scale reactor comparison experiments. In addition, grab samples of mixed liquor and waste AS (WAS) from a full-scale domestic wastewater treatment plant (WTP, California, USA, July 2002) was used for comparison experiments. Prior to use the sludge was settled overnight at $4^{\circ} \mathrm{C}$, the supernatant decanted and an equal amount of fresh AS feed added. The sludge was then continuously mixed overnight at room temperature, before being distributed into flasks for the batch experiments. The different sludge samples were from reactors operated under different process conditions with different feed types. For the purposes of this study the total and volatile suspended solids (TSS and VSS) concentrations as defined in Standard Methods (1998) were the primary attribute used to characterise the sludge. No attempt was made to identify differences in microbial populations.

\section{Batch activated sludge experiments oestrogenic activity reduction trends}

Batch experiments were set up with $100 \mathrm{~m} \ell$ of AS in $250 \mathrm{~m} \ell$ baked glass flasks. The AS experiments were spiked with E2 standards to give final E2 concentrations of $20 \mathrm{mg} / \ell, 100 \mu \mathrm{g} / \ell$ and $100 \mathrm{ng} / \ell$. In one set of flasks the contents were mixed continuously (mixed test) while the other was allowed to stand (nonmixed test). Controls with no E2, and no sludge respectively were included. The un-mixed reduction test used was similar to that described in an early study of oestrogen removal by Tabak and Bunch (1970). $250 \mathrm{~m} \ell$ glass conical flasks were used for each test set. Into the flasks was added AS feed ( Ng, 2001), presettled AS, and estradiol in ethanol or ethanol only, according to the matrix given in Table 1. The amount of AS used depended on the target suspended solids concentration for the given experiments. Target solids concentrations were grouped as: $<1$ to 1 $\mathrm{gTSS} / \ell, 1$ to $2 \mathrm{gTSS} / \ell$, and 2 to $4 \mathrm{gTSS} / \ell$. Actual TSS and VSS ranges were: 0.16 to $0.93 \mathrm{gTSS} / \ell$ ( 0.16 to $0.73 \mathrm{gVSS} / \ell$ ), 1.01 to $1.53 \mathrm{gTSS} / \ell$ ( 0.79 to $1.19 \mathrm{gVSS} / \ell)$, and 2.42 to $3.58 \mathrm{gTSS} / \ell$ (1.74 to $2.82 \mathrm{gVSS} / \ell$ ).

Tests were carried out for E2 spikes of $20 \mathrm{mgE} 2 / \ell, 100$ $\mu \mathrm{gE} 2 / \ell$ and $100 \mathrm{ngE} 2 / \ell$. These concentrations represent a very large range. As mentioned previously, Tabak et al. (1981) estimated the water solubility of $17 \beta$-estradiol at about $13 \mathrm{mg} / \ell$ in removal studies with a $20 \mathrm{mgE} 2 / \ell$ spike. A test concentration of $20 \mathrm{mg} / \ell$ therefore represents a situation in which solubility of the oestrogen is a limiting factor as some of the oestrogen will remain in suspension in the aqueous phase. This E2 concentration was included in order to compare findings with those of early studies.

Typical E2 concentrations in raw and treated wastewater are

\begin{tabular}{|l|c|c|c|c|}
\hline \multicolumn{5}{|c|}{$\begin{array}{c}\text { TABLE 1 } \\
\text { Design matrix for oestrogenic activity reduction } \\
\text { batch-reactor tests }\end{array}$} \\
\hline $\begin{array}{l}\text { Flask } \\
\text { number }\end{array}$ & I & II & III & IV \\
\hline AS feed & Yes & Yes & Yes & Yes \\
\hline AS & Yes & Yes & No & No \\
\hline E2 in EtOH & Yes & No & No & Yes \\
\hline EtOH & No & Yes & Yes & No \\
\hline Description & $\begin{array}{c}\text { Spiked AS } \\
\text { experiment }\end{array}$ & $\begin{array}{c}\text { AS } \\
\text { control }\end{array}$ & $\begin{array}{c}\text { AS feed } \\
\text { control } \\
\text { without E2 }\end{array}$ & $\begin{array}{c}\text { AS feed } \\
\text { control } \\
\text { with E2 }\end{array}$ \\
\hline
\end{tabular}

Yes $=$ present $;$ No $=$ absent up to $20 \mathrm{ng} / \ell$, and up to $50 \mathrm{ng} / \ell$ have been measured (Desbrow et al., 1998; Belfroid et al., 1999; Layton et al., 2000). The test concentration of $100 \mathrm{ng} / \ell$ was chosen to represent the highest possible typical concentration in water influent to the AS system, assuming that no E2 is removed in prior treatment processes. To attain the desired final dose, the appropriate standard stock could be used to keep the spike volume to less than $1 \%$ of the total. Flasks with no E2 $(0 \mathrm{mgE} 2 / \ell)$ and no sludge $(0 \mathrm{gVSS} / \ell)$ were included as controls.

For the un-mixed experiments, the flasks were allowed to stand at the ambient room temperature $\left(26.6 \pm 1.3{ }^{\circ} \mathrm{C}\right)$ for the duration of the experiment. Prior to sampling the flask contents were mixed by swirling for $15 \mathrm{~s}$ and then a $2 \mathrm{~m} \ell$ sample was collected using a flask-dedicated pipette tip rinsed in alcohol and nanopure water. Samples were collected up to 10 separate times over the $15 \mathrm{~d}$ test periods. The samples were stored in baked glass test tubes, covered with parafilm, and frozen until the assay. This was done so that each set of samples could be assayed using the same yeast culture used to assay the set of standards which were included to estimate the E2-equivalent concentrations. The entire 15 d set of samples were thawed overnight in the refrigerator $\left(4^{\circ} \mathrm{C}\right)$ for the yeast assay the next day. Each sample was centrifuged at $3600 \mathrm{r} / \mathrm{min}(2140 \mathrm{x} \mathrm{g})$ for $10 \mathrm{~min}$ to separate out the solids. $250 \mu \ell$ of supernatant was then used in the place of the standard as described in the outlined assay protocol.

\section{Results and discussion}

\section{AS feed controls - no sludge, no E2 control}

$15 \mathrm{~d}$ sets of control experiments with flasks containing AS feed only were included to account for any oestrogenic activity of the sludge feed. The induced oestrogenic activity in the assays of AS feed samples was $0.048 \pm 0.018 \mu \mathrm{mol} / \mathrm{m} \ell$-min (activity ratio $=$ $0.197 \pm 0.160 ; \mathrm{n}=6$ sets) for mixed experiments and $0.042 \pm 0.015$ $\mu \mathrm{mol} / \mathrm{m} \ell$-min (activity ratio $=0.101 \pm 0.126 ; \mathrm{n}=3$ sets) for unmixed experiments.

\section{AS feed dosed with E2 - no sludge control}

To check if there was reduction of oestrogenic activity in samples without sludge, flasks with sterile AS feed were dosed with E2. Three $15 \mathrm{~d}$ sets each were carried out for E2 spiked doses of $100 \mathrm{ng} / \ell, 100 \mu \mathrm{g} / \ell$ and $20 \mathrm{mg} / \ell$ and a summary of results

\begin{tabular}{|l|l|l|l|}
\hline \multicolumn{4}{|c|}{ TABLE 2 } \\
Oestrogenic activity in sludge-free controls \\
spiked with E2
\end{tabular}


is presented in Table 2. The variation in activities - measured as the standard deviation from the mean of the sample activities - is highest for the $20 \mathrm{mgE} 2 / \ell$ dose. This may be attributed to the fact that the dose level is above the known solubility and the E2 is partly un-dissolved at the start of the experiment.

It was important to define any abiotic reduction (due to chemical degradation, sorption to flask walls, etc.) in case it was a significant factor in the reduction of the oestrogenic activity. While other studies used sterile mineral medium (Andersen et al., 2004) to study abiotic reduction, in this study the AS feed was used so that matrix consistency was preserved. However, the presence of colloidal solids in the feed constituents may have affected the recoveries obtained at lower E2 concentrations since the mean recovery was found to be concentrationdependent (Table 2). The importance of colloidal solids in the biological treatment of wastewater containing oestrogens has been discussed by Holbrook et al. (2003a; 2004). Andersen et al. (2004) found that there was no clear tendency for reduction of $\mathrm{E} 2$ in the abiotic experiments, and obtained an approximately $75 \%$ recovery of the $500 \mathrm{ng} / \ell$ spike after a $96 \mathrm{~h}(4 \mathrm{~d})$ experiment period.

\section{AS with no dosed E2 added - no E2 control}

The background oestrogenic activity of the sludge used for the experiments is an important factor, especially at low concentrations because the yeast assay is quite sensitive. Controls without E2 were dosed with an equivalent amount of EtOH vehicle used to dissolve the E2 in the standards (always less than $1 \%$ by volume). They did not show high oestrogenic activity over time (activity ratio less than 0.2 ).

Mixed experiments with fed AS but no E2 dose induced an activity of $0.028 \pm 0.015 \mu \mathrm{mol} / \mathrm{m} \ell$-min (activity ratio $=$ $0.051 \pm 0.109 ; \mathrm{n}=10$ sets) while the un-mixed experiments present lower background activities $(0.028 \pm 0.009 \mu \mathrm{mol} / \mathrm{m} \ell$ min; activity ratio $=0.009 \pm 0.096 ; \mathrm{n}=5$ sets $)$. When normalised by sludge TSS concentration the activity ratios decrease slightly to $0.029 \pm 0.085(\mathrm{n}=8$ sets $)$ for mixed experiments and $0.028 \pm 0.018(\mathrm{n}=3 \mathrm{sets})$ for un-mixed experiments. The presence of sludge reduces the background activity detected in the feed alone, suggesting either possible interference by colloidal solids on detection of oestrogenic activity by the yeast assay or preferential association of any oestrogenic compounds in the feed with the solids removed by centrifugation. Colloidal solids are important as they adsorb oestrogens (Holbrook et al., 2003a; Holbrook et al., 2004), a factor which may be further improved with a higher solids organic content (Lai et al., 2000) as would be expected in activated sludge. An early study by Scherrer et al. (1974) reported that the isolated yeast cell wall may exclude compounds with an average hydrodynamic radius larger than $0.8 \mathrm{~nm}$ and average molecular weight greater than $620 \mathrm{~g} / \mathrm{mol}$, and the yeast cell membrane preferentially internalises lipophilic compounds, so it is possible that some oestrogenic compounds may not be detected by the assay, especially

if the compounds are associated with colloidal solids.

\section{Batch experiments with sludges from laboratory- scale sequencing batch reactors and a full-scale wastewater treatment plant}

Figure 1 shows the results from the experiments with activated sludges from 3 different sources. Before E2 dosing, the total oestrogenic activity of the sludge supernatant was not distinguishable from the assay blank. The AS from the laboratoryscale sequencing batch reactors (SBR \#1 and SBR \#2) required a lag time of about $10 \mathrm{~d}$ to remove oestrogenic activity from the supernatant when initially spiked with $100 \mu \mathrm{gE} 2 / \ell$, while that from the full-scale treatment plant (WTP) did not. A similar observation was made by Lee and Liu (2002) on experiments with sludge supernatant from an Ontario treatment plant. This may be due to the fact that all the laboratory reactors were fed with artificial wastewater with little or no oestrogenic activity added. While there was some variability in the feed used during the batch experiment (see section on sludge-free, E2-free controls), oestrogenic activity was defined by a mean activity ratio of less than 0.2. To counter this feed effect, all standards were prepared in the same AS feed that was used for a given batch 


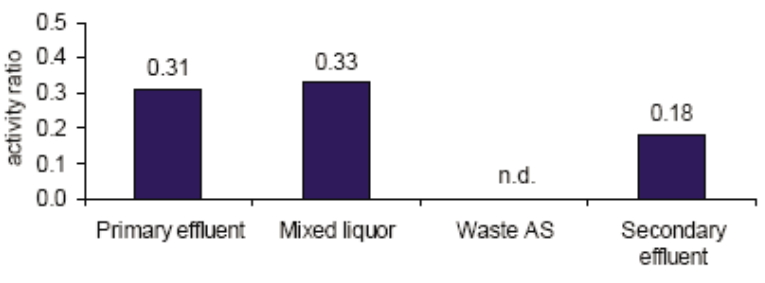

sample type

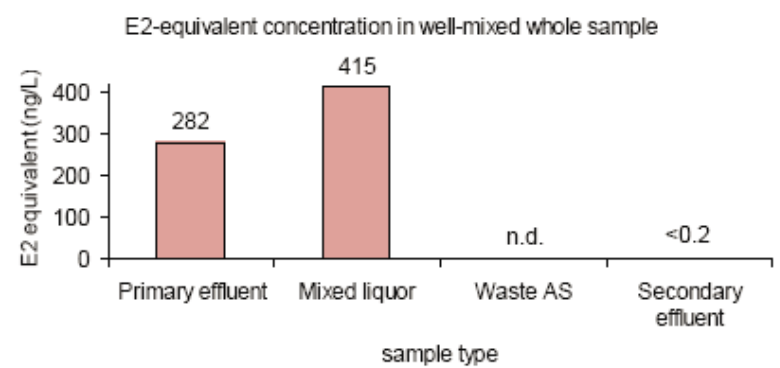

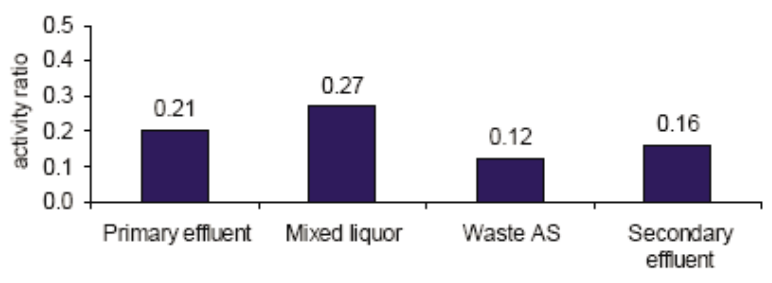

sample type

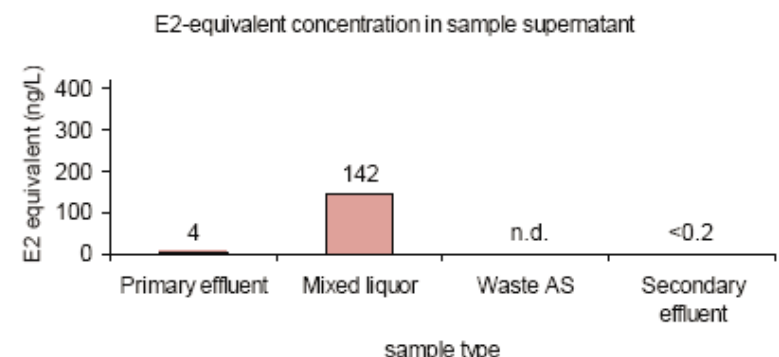

sample type

Figure 2

Total oestrogenic activity and estimated E2-equivalent concentrations in grab samples from different locations in the full-scale WTP activated sludge system. Note that the waste settled AS (5 gVSS/l) exhibits lower activity than the effluent, and in the supernatant, suggesting that oestrogenic activity associated with suspended solids is less available for detection in the yeast assay. [n.d. = not distinguishable from the assay blank].

experiment, and in most cases a large amount of concentrated stock feed was prepared and diluted as necessary.

When re-spiked on Day 16 (see arrows in Fig. 1) the SBR sludges removed oestrogenic activity within a shorter time (within $5 \mathrm{~d}$ ) - suggesting that the sludge had become acclimatised to the presence of a relatively high concentration oestrogen. The AS micro-organisms from both SBRs \#1 and \#2 had been selectively cultured for enhanced biological phosphorus removal (EBPR) over a number of years in a laboratory environment and had been fed with an artificial wastewater feed during that time (Harper, 2002; McMahon, 2002). On the other hand the sludge from the full-scale treatment plant - which is expected to receive domestic wastewater with fluctuating levels of natural and synthetic oestrogens - removed oestrogenic activity to background levels within $5 \mathrm{~d}$ from dosing both with and without acclimatisation.

It is not known at this time why the SBR \#2 activated sludge sample induced an assay response equivalent to a dose up to 4 times higher than the initial spiked doses, but similar responses were seen with other samples in this study. In other studies it has been observed that when biological responses to are converted to E2-equivalent concentration, there may be a discrepancy due to the presence of compounds which may contribute to oestrogenic activity even at low concentrations (Onda et al., 2003; Pawlowski et al., 2003). Also it was observed that SBR\#1 sludge did not remove total oestrogenic activity to non-detectable levels even after re-spiking. A similar residual response was observed in a study by Servos et al. (2005) where in aerobic batch experiments with a sewage sludge able to reduce E2 and E1 by $>95 \%$ in less than $24 \mathrm{~h}$, traces of yeast assay response were detected even after $5 \mathrm{~d}(120 \mathrm{~h})$.

\section{Estimated E2-equivalent concentrations of grab samples from a full-scale wastewater treatment plant}

Grab samples from the full-scale activated sludge system (WTP) were assayed for total oestrogenic activity. The samples were collected on July 2002 in baked glass jars and aliquots stored frozen until analysis. The samples were thawed overnight at $4{ }^{\circ} \mathrm{C}$ for the assay. Both well-mixed whole samples, and supernatant from centrifuged samples were assayed. There is an apparent reduction of total oestrogenic activity in the activated sludge system (see Fig. 2).

To estimate the E2-equivalent concentrations of the grab samples shown in Fig. 2, the activity of the assay blank [AR = 0.2] was subtracted from all sample activities to give the sample AR. Then using the sample AR, an estimate of the E2 concentration which would induce an equivalent activity was interpolated from the standard curve. Samples marked "n.d." induced an activity indistinguishable from the assay blank.

\section{Effect of increasing sludge TSS and of pre-exposing sludge to oestrogen}

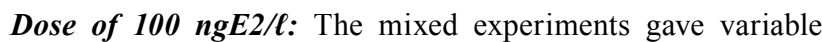
results. At sludge concentrations of less than $1 \mathrm{gTSS} / \ell$ there were slightly improved oestrogenic activity reductions when the experiments were re-spiked with E2 on the $16^{\text {th }}$ day of the experiments (see arrows on Fig. 3 showing re-spike). At $0.62 \mathrm{gTSS} / \ell$ $(81 \% \mathrm{VS})$ reduction increased from $109 \%$ to $110 \%$ while at 0.86 gTSS $/ \ell(77 \% \mathrm{VS})$ reduction increased from $42 \%$ to $46 \%$. When TSS was increased, the total oestrogenic activity reductions changed as well. At $1.53 \mathrm{gTSS} / \ell(78 \% \mathrm{VS})$ reductions improved from $79 \%$ to $102 \%$ after re-spiking while at $1.98 \mathrm{gTSS} / \ell(77 \%$ VS), reduction decreased from $84 \%$ to $75 \%$. With sludge concentrations above $2 \mathrm{gTSS} / \ell$ ( $2.36 \mathrm{gTSS} / \ell, 73 \% \mathrm{VS} ; 3.4 \mathrm{gTSS} / \ell$, $92 \% \mathrm{VS}$; and $3.58 \mathrm{gTSS} / \ell, 75 \% \mathrm{VS})$ there was an overall increase in oestrogenic activity at the end of the experiment (Day 30/31) after re-spiking. Extending the experiment by an additional $5 \mathrm{~d}$ reduced the activity to background levels at Day 36/37.

In a full-scale AS treatment plant, this would mean that longer solids retention times (SRT) should enhance oestrogenic activity removal by allowing a longer contact time for the removal of compounds which contribute to oestrogenic activity. Andersen et al. (2004) for example predicted higher oestrogen removals in a Danish treatment plant with an SRT of approximately 35 
d compared with a treatment plant with a 20 to $25 \mathrm{~d}$ SRT. Holbrook et al. $(2002 ; 2003 b)$ reported higher specific equivalent estradiol activity $(\mu \mathrm{g}$ E2-equivalent $/ \mathrm{kg}$ TSS) for facilities utilising secondary clarification when the SRT was 20 to $25 \mathrm{~d}$ compared with 8 to 12 d. A study by Svenson et al. (2003) on samples from several Swedish treatment plants showed that the plants with biological treatment (including an activated sludge process) and longer retention times had higher reductions of estradiol equivalents. At $100 \mathrm{ngE} 2 / \ell$ doses, the reduction was shown to be enhanced both by increasing VSS concentrations and continuous mixing. $100 \mathrm{ngE} 2 / \ell$ is close to the lower quantification limit of the assay and the data are more variable over time. E2-equivalent concentrations greater than 4 times the spiked dose were omitted since recovery experiments did not support their validity.

Dose of $100 \mu g E 2 / \ell$ : Experiments spiked with $100 \mu \mathrm{gE} 2 / \ell$ (Fig. 4) showed $>20 \%$ reduction of oestrogenic activity within $15 \mathrm{~d}$ on average. Re-spiking the sludge with an additional $100 \mu \mathrm{g} / \ell$ on the $16^{\text {th }}$ day after the first set of experiments either resulted in additional reduction or an increase in total oes-

Figure 3 (top right) Reduction of oestrogenic activity induced by a spiked dose of $100 \mathrm{ngE2} / \mathrm{l}$ in all continuously mixed and unmixed batch experiments.

There is $>40 \%$ reduction of total oestrogenic activity detected from the sludge supernatant after $15 \mathrm{~d}$. The percent reduction increases slightly when the experiments are re-spiked on Day 16. Arrows show re-spike.

Figure 4 (bottom right)

Reduction of oestrogenic activity induced by a spiked dose of $100 \mu \mathrm{gE} 2 / \ell$ in all continuously mixed and unmixed batch experiments. The reduction of oestrogenic activity at this dose varied, ranging from sludges requiring 3 to $10 \mathrm{~d}$ of lag-time for reduction to background levels to some sludges removing only $20 \%$ of the doseinduced activity. Experiments with $1 \mathrm{gTSS} / \mathrm{l}$ or less were able to reduce oestrogenic to background levels both with and without mixing. Some sludges lost their ability to reduce the oestrogenic activity after the re-spike (see arrows for re-spike), while others reduced the oestrogenic activity within a shorter time.
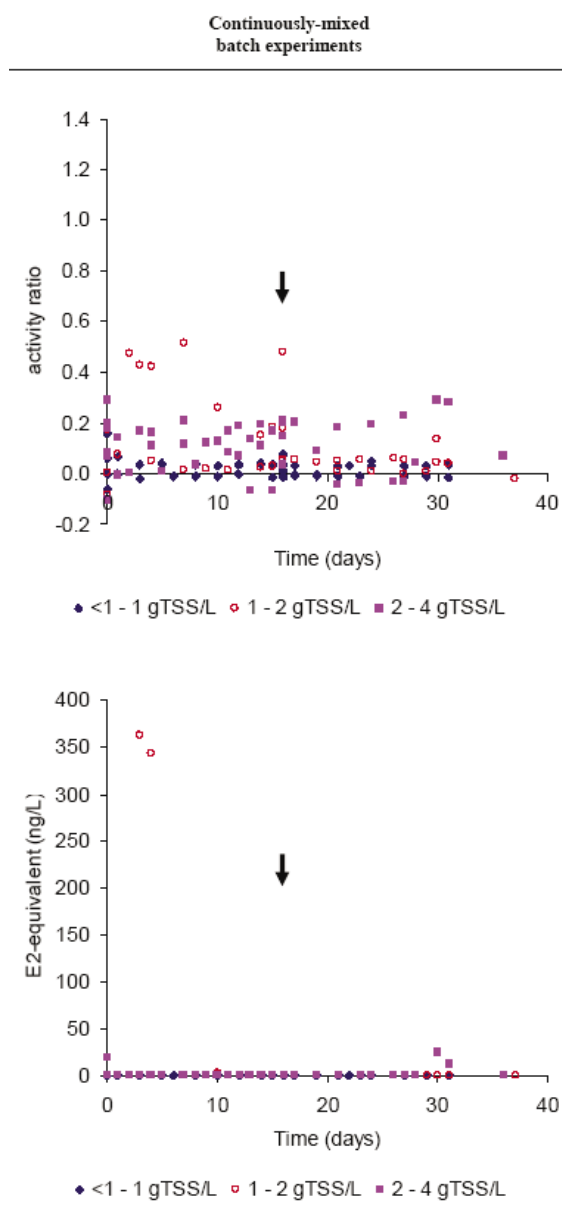
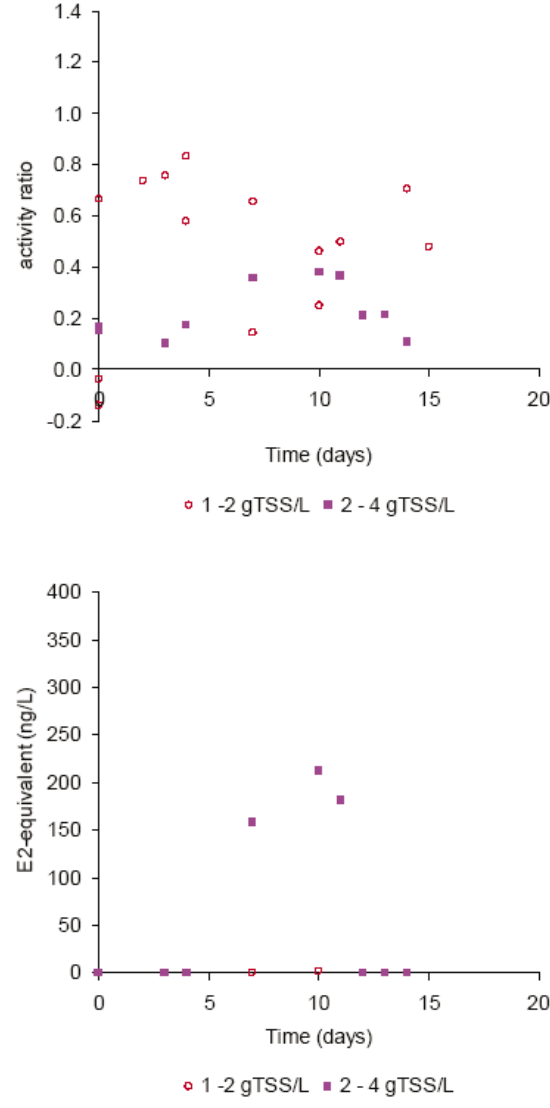

- $1-2 \mathrm{gTSS} / \mathrm{L}=2-4 \mathrm{gTSS} / \mathrm{L}$

- 1 -2 gTSS/L - 2 - 4 gTSS/L

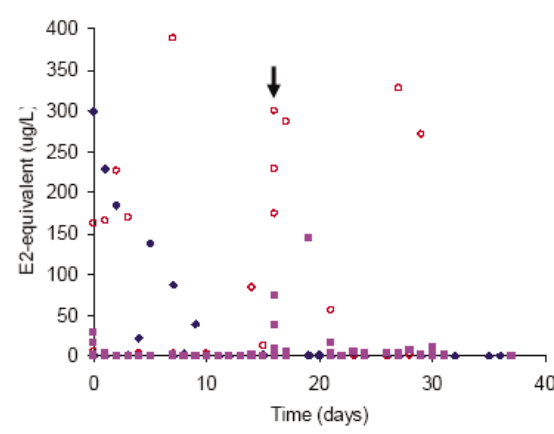

- $<1-1 \mathrm{gTSS} / \mathrm{L}$ o $1-2 \mathrm{gTSS} / \mathrm{L}=2-4 \mathrm{gTSS} / \mathrm{L}$
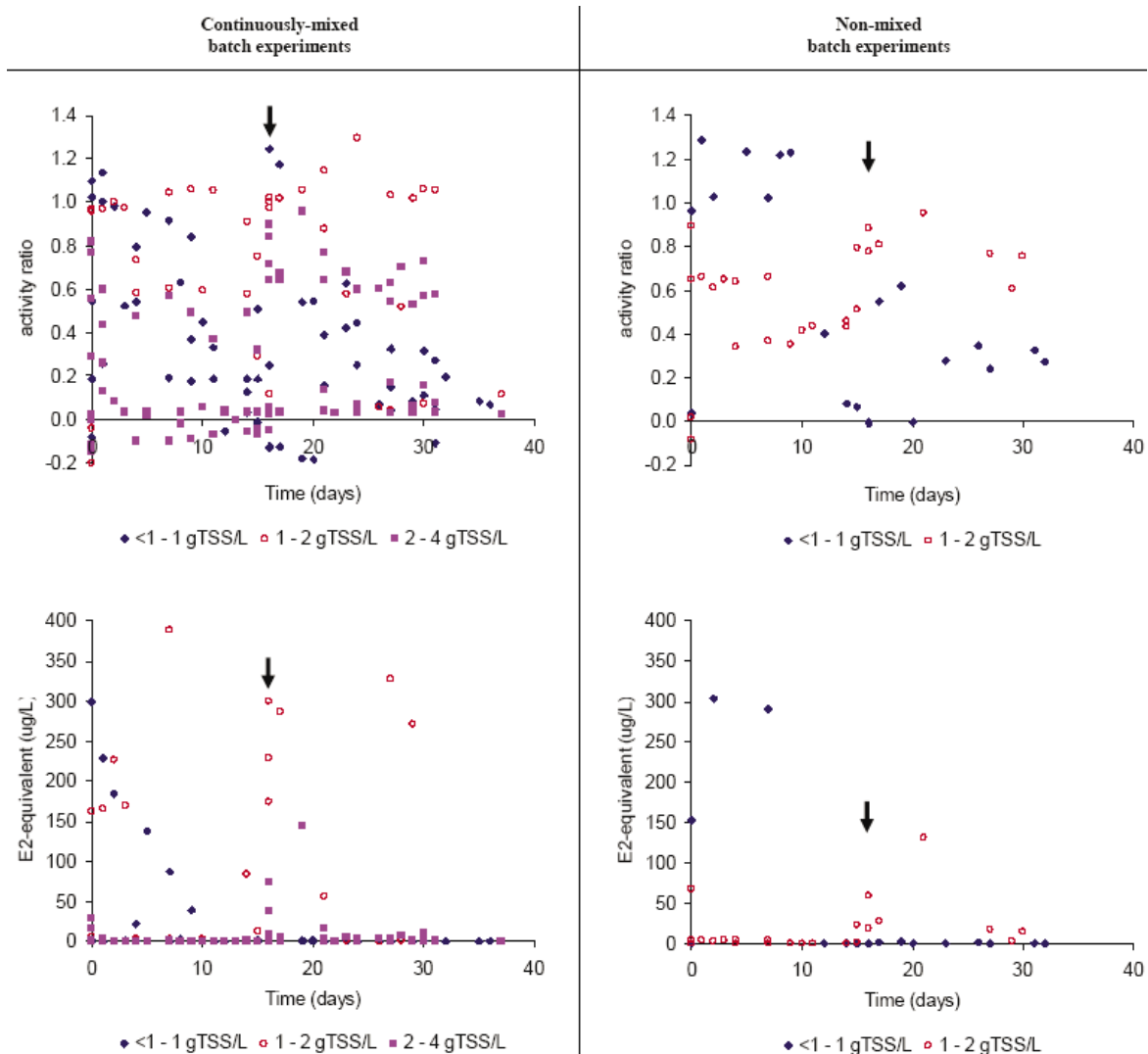

- $<1$ - 1 gTSS/L o $1-2$ gTSS/L 


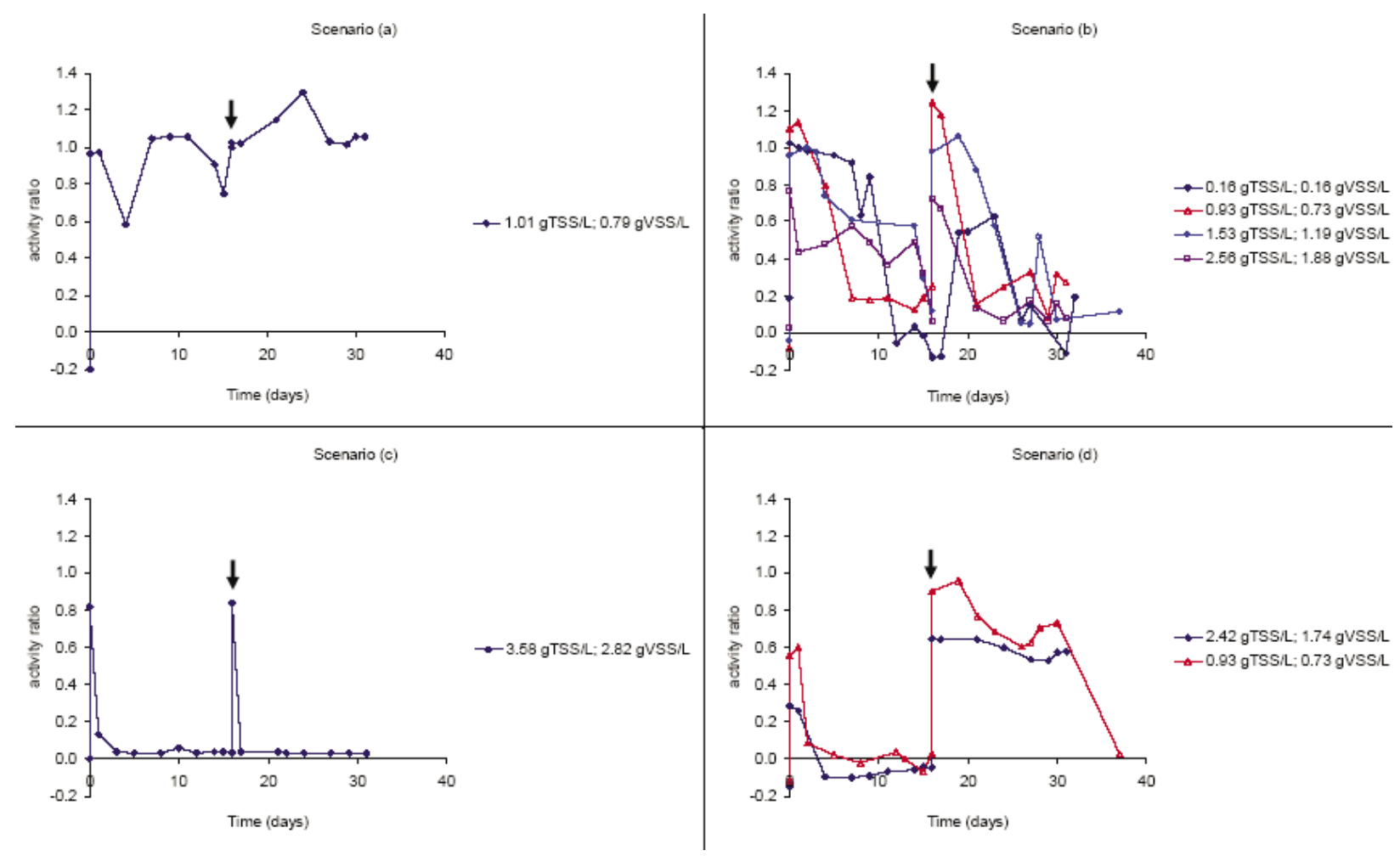

Figure 5

The four scenarios observed for reduction of total oestrogenic activity induced by a spiked dose of $100 \mu \mathrm{gE2} / \mathrm{l}$ in continuously mixed batch experiments. Most of the reductions followed Scenario (b), i.e. there was a lag time before removal to background levels at the end of the first $15 \mathrm{~d}$ period, and the sludges required a shorter lag-time after the re-spike.

trogenic activity. It is not clear why there would be no reduction in some of the experiments after re-spiking as the lack of reduction appeared to have no relationship with the TSS or VSS concentrations. Further study is required to establish whether this phenomenon is due to loss of sorption capacity (saturation of available sites) or due to compromised microbial metabolism.

In general, the oestrogenic activity induced in continuously mixed batch experiments by an E2 spike of $100 \mu \mathrm{g} / \ell$ followed four scenarios (Fig. 5):

a There was hardly any reduction of oestrogenic activity at the end of the $15 \mathrm{~d}$ or $30 \mathrm{~d}$ period $(1.01 \mathrm{gTSS} / \ell)$

b After an initial lag time there was some removal or removal to background levels by the end of the first $15 \mathrm{~d}$ period, and after the re-spike a shorter lag time was required to reduce oestrogenic activity to background levels $(0.16,0.93,1.53$, and $2.56 \mathrm{gTSS} / \ell$ )

c There was a reduction of oestrogenic activity to background levels within the first $3 \mathrm{~d}$ after E2 dosing both before and after the re-spike ( $3.58 \mathrm{gTSS} / \ell)$

d There was a reduction of oestrogenic activity to background levels within the first $5 \mathrm{~d}$ after E2 dosing, but there was little or no reduction after the re-spike (2.42 and $0.93 \mathrm{gTSS} / \ell)$.

At $100 \mu \mathrm{gE} 2 / \ell$ dose there is an enhancement of oestrogenic activity reduction with AS present as control experiments without sludge showed little reduction of oestrogenic activity over time. Mixing the sludge also improves reduction at this dose for TSS concentrations above $1 \mathrm{gTSS} / \ell$. Below $1 \mathrm{gTSS} / \ell$ sludges removed $>70 \%$ of the induced oestrogenic activity before and after re-spiking, and with or without mixing. At higher TSS however, the unmixed sludges removed $20 \%$ of the induced oestrogenic activity after
$15 \mathrm{~d}$. The re-spiked experiment removed only $2 \%$ of the oestrogenic activity by Day 30, underscoring the fact that mixing is important for long-term oestrogenic activity reduction capacity.

Batch experiments by Lee and Liu (2002) showed that sludge supernatant $(<1$ gTSS/ $\ell)$ degraded E2 and its metabolites very rapidly under aerobic conditions. Within $22 \mathrm{~h}$ after dosing 200 $\mu \mathrm{gE} 2 / \ell$ they measured an almost quantitative oxidation of twothirds of the E2 to E1. Although less than $10 \%$ of the dosed E2 was detectable after $48 \mathrm{~h}$, the concentration of E1 increased by over $50 \%$ within $3 \mathrm{~d}$ and did not drop below $10 \%$ until more than $10 \mathrm{~d}$ had passed (Lee and Liu, 2002). This confirms the observations in this study that more than 10 to $14 \mathrm{~d}$ are required to remove total oestrogenic activity from sludge supernatant after spiked doses of $100 \mu \mathrm{gE} 2 / \ell$ or more. Any oestrogen removal monitoring regime would then need to follow the fate of both E2 and E1 simultaneously. This would be complicated in a fullscale treatment plant AS system which receives new oestrogen loads continuously, and in addition to sludge recycling has micro-organisms with enzymes to metabolise and de-conjugate oestrogenic compounds.

The complex and varied responses observed in this study may be attributed to the complex nature of the sample. While every attempt was made to replicate the experiments, it was not possible to duplicate the TSS and VSS concentrations exactly even with AS from the same source. The different batch experiments may therefore have different responses due to different TSS and VSS concentrations, different suspended solids compositions, different microbial communities, and a different predisposition for oestrogen reduction. It is expected that the behaviour of the oestrogenic activity - activated sludge relationship in a full-scale treatment plant would be just as complex if not more so. 
The response to, and reduction of, oestrogenic activity in activated sludge systems is then a combination of the types and quantities of oestrogenic compounds present, the suspended solids compositions and the microbial community make-up. In this study, the type and quantity of oestrogenic compounds present was defined by the spiked E2 dose and the total and volatile suspended solids concentrations were used as a surrogate for the suspended solids composition, including the organic solids and microbial community. However, in this complex mixture, the reduction of oestrogenic activity is primarily due to sorption of the hydrophobic oestrogens to the organic AS solids and metabolism by the consortia of micro-organisms that make up the AS. In order to differentiate the effects of microbial metabolism and sorption to solids on the reduction of total oestrogenic activity it was necessary to either remove the solids (as in the AS-free controls described in this study) or eliminate the microbial metabolism by sterilising the sludge.

The next step is then to apply the oestrogen-sensitive yeast assay to study the reduction of oestrogenic activity obtained in batch experiments with sterile sludge. Experiments with sterilised activated sludge are being planned and the results will be compared with findings from recent studies including studies by Jensen and Schäfer (2001) comparing the sorption of oestrogens to different particulate solids including activated sludge and cellulose, and by Clara et al. (2004) in which the sludge was inactivated using mercury (II) sulphate, and a comprehensive study of oestrogen sorption using washed, heat-sterilised sludge published by the Danish Environmental Protection Agency (Andersen et al., 2004).

\section{Conclusions}

- From the results of the batch experiments with activated sludges from laboratory reactors and a full-scale treatment plant, it was observed that the AS from the laboratory reactors required a lag time of days to remove E2-induced total oestrogenic activity when initially spiked with $100 \mu \mathrm{gE} 2 / \ell$ while the AS from the full-scale plant did not. The laboratory reactor sludges showed an improved oestrogenic activity reduction capability after re-spiking.

- At $100 \mathrm{ng}$ E2/ $\ell$ spiked dose, total oestrogenic activity reduction is enhanced both by increasing activated sludge TSS and VSS concentration and by continuous mixing.

- For the E2 doses in the study, many sludges required more than 10 to $14 \mathrm{~d}$ to remove total oestrogenic activity from AS supernatant to background levels due to the oestrogenic nature of the metabolites of E2.

- Acclimation of the AS to E2, by dosing and re-spiking, may improve E2-induced oestrogenic activity reduction in some cases. In general, increasing sludge TSS concentrations also improved oestrogenic activity reduction, but TSS concentrations between 1 and 2 gTSS/ $\ell$ gave the most varied responses in the batch experiments.

- The relationship between oestrogenic activity and organic suspended solids is a complex one and merits further study.

\section{Acknowledgements}

The authors would like to thank the University of California Center for Water Resources for funding part of this research under Project No. W-944; Dr D Picard for generously providing the yeast parent strain and oestrogen-sensitive yeast construct; $\mathrm{H} \mathrm{Ng}$ for providing the activated sludge and activated sludge feed; K McMahon, W Harper, and R Merlo for activated sludge samples. E Wozei was supported in part by a fellowship grant from the Norwegian Council of Universities' Committee for Development Research and Education (NUFU).

\section{References}

ANDERSEN HR, KJOLHOLT J, HANSEN M, STUER-LAURIDSEN F, BLICHER TD, INGERSLEV $F$ and HALLING-SORENSEN B (2004) Degradation of Estrogens in Sewage Treatment Processes. Environmental Project No. 899. Danish Environmental Protection Agency, Danish Ministry of the Environment. $61 \mathrm{pp}$.

ARNOLD SF, ROBINSON MK, NOTIDES AC, GUILLETTE LJ, JR. and McLACHLAN JA (1996) A yeast estrogen screen for examining the relative exposure of cells to natural and xenoestrogens. Environ. Health Perspect. 104 (5) 544-548.

ATKINSON S, ATKINSON MJ and TARRANT AM (2003) Estrogens from sewage in coastal marine environments. Environ. Health Perspect. 111 (4) 531-535.

BECERRA M, DÍAZ PRADO S, GONZÁLEZ SISO MI and CERDÁN ME (2001) New secretory strategies for Kluyveromyces lactis ß-galactosidase. Protein Eng. 14 (5) 379-386.

BELFROID AC, VAN DER HORST A, VETHAAK AD, SCHÄFER AJ, RIJS GBJ, WEGENER J and COFINO WP (1999) Analysis and occurrence of estrogenic hormones and their glucuronides in surface water and waste water in The Netherlands. Sci. Total Environ. 225 (225) 101-108.

CLARA M, STRENN B, SARACEVIC E and KREUZINGER N (2004) Adsorption of bisphenol-A, 17 beta-estradiole and 17 alphaethinylestradiole to sewage sludge. Chemosphere 56 (9) 843-851.

COLDHAM NG, DAVE M, SIVAPATHASUNDARAM S, MCDONNELL DP, CONNOR C and SAUER MJ (1997) Evaluation of a recombinant yeast cell estrogen screening assay. Environ. Health Perspect. 105 (7) 734-742.

D'ASCENZO G, DI CORCIA A, GENTILI A, MANCINI R, MASTROPASQUA R, NAZZARI M and SAMPERI R (2003) Fate of natural estrogen conjugates in municipal sewage transport and treatment facilities. Sci. Total Environ. 302 (1-3) 199-209.

DESBROW C, ROUTLEDGE EJ, BRIGHTY GC, SUMPTER JP and WALDOCK M (1998) Identification of estrogenic chemicals in STW effluent 1: Chemical fractionation and in vitro biological screening. Environ. Sci. Technol. 32 (11) 1549-1558.

FÜRHACKER M, BREITHOFER A and JUNGBAUER A (1999) 17ßestradiol: Behavior during wastewater analyses. Chemosphere 19 (11) 1903-1909.

HANSCH C, LEO A and HOEKMAN D (1995) Exploring QSAR 2: Hydrophobic, Electronic, and Steric Constants. American Chemical Society, Washington, DC. 368 pp.

HARPER WF (2002) Application of Anaerobic/Aerobic Activated Sludge to Nutrient-Deficient Wastewater Treatment. Unpublished Doctoral Dissertation, University of California at Berkeley. 33-34.

HERMANOWICZ SW and WOZEI E (2002) Biodegradation of Estrogenic Compounds and its Enhancement in a Membrane Bioreactor. Technical Completion Report, Project Number W-944. University of California Water Resources Center. 11 pp.

HOLBROOK RD, LOVE NG and NOVAK JT (2003a) Biological wastewater treatment and estrogenic endocrine disrupting compounds: Importance of colloid organic carbon. Pract. Period. of Haz. Toxic Radioact. Waste Manage. 7 (4) 289-296.

HOLBROOK RD, LOVE NG and NOVAK JT (2004) Sorption of 17beta-estradiol and 17alpha-ethinylestradiol by colloidal organic carbon derived from biological wastewater treatment systems. Environ. Sci. Technol. 38 (12) 3322-3329.

HOLBROOK RD, NOVAK JT, GRIZZARD TJ and LOVE NG (2002) Estrogen receptor agonist fate during wastewater and biosolids treatment processes: A mass balance analysis. Environ. Sci. Technol. 36 (21) 4533-4539.

HOLBROOK RD, NOVAK JT, GRIZZARD TJ and LOVE NG (2003b) Response to comment on "Estrogen receptor agonist fate during wastewater and biosolids treatment processes: A mass balance analysis”. Environ. Sci. Technol. 37 (20) 4821-4822. 
HU J-Y, AIZAWA T and KUNIKANE S (2000) Quantitative structureactivity relationships for estrogen receptor binding affinity of phenolic compounds. Proc. $1^{\text {st }}$ World Water Congress of the Int. Water Assoc. (IWA) Paris. 5 pp.

HUANG C-H and SEDLAK DL (2001) Analysis of estrogenic hormones in municipal wastewater effluent and surface using enzyme-linked immunosorbent assay and gas chromatograph/tandem mass spectrometry. Environ. Toxicol. Chem. 20 (1) 133-139.

JENSEN RL and SCHÄFER AI (2001) Adsorption of estrone and 17 beta-estradiol by particulates - activated sludge, bentonite, hematite and cellulose. Proc. Recent Adv. Water Recycling Technol. Brisbane Workshop. Brisbane, Australia. 93-102.

JOHNSON AC, WILLIAMS RJ and ULAHANNAN T (1999) Comment on "Identification of estrogenic chemicals in STW effluent. 1 Chemical fractionation and in vitro biological screening". Environ. Sci. Technol. 33 (2) 369-370.

JOYEUX A, BALAGUER P, GERMAIN P, BOUSSIOUX AM, PONS $M$ and NICOLAS JC (1997) Engineered cell lines as a tool for monitoring biological activity of hormone analogs. Anal. Biochem. 249 119-130.

JURGENS MD, HOLTHAUS KIE, JOHNSON AC, SMITH JJL, HETHERIDGE M and WILLIAMS RJ (2002) The potential for estradio and ethinylestradiol degradation in English rivers. Environ. Toxicol. Chem. 21 (3) 480-488.

KERTESZ MA (1999) Riding the sulfur cycle - metabolism of sulfonates and sulfate esters in gram-negative bacteria. FEMS Microbiol. Rev. 24 135-175.

KLEIN KO, BARON J, COLLI MJ, MCDONNELL DP and CUTLER GB (1994) Estrogen levels in childhood determined by an ultrasensitive recombinant cell bioassay. J. Clin. Invest. 94 (6) 2475-2480.

KÖRNER W, BOLZ U, SUSSMUTH W, HILLER G, SCHULLER W, HANF V and HAGENMAIER H (2000) Input/output balance of estrogenic active compounds in a major municipal sewage plant in Germany. Chemosphere 40 (9-11) 1131-1142.

KYOTO ENCYCLOPEDIA OF GENES AND GENOMES. www genome.ad.jp/kegg. Accessed on 2 March 2004.

LAI KM, JOHNSON KL, SCRIMSHAW MD and LESTER JN (2000) Binding of waterborne steroid estrogens to solid phases in river and estuarine systems. Environ. Sci. Technol. 34 (18) 3890-3894.

LAYTON AC, GREGORY BW, SEWARD JR, SCHULTZ TW and SAYLER GS (2000) Mineralization of steroidal hormones by biosolids in wastewater treatment systems in Tennessee, USA. Environ. Sci. Technol. 34 (18) 3925-3931.

LEE HB and LIU D (2002) Degradation of 17 beta-estradiol and its metabolites by sewage bacteria. Water Air Soil Pollut. 134 (1-4) 353-368.

LEGLER J, JONAS A, LAHR J, VETHAAK AD, BROUWER A and MURK AJ (2002) Biological measurement of estrogenic activity in urine and bile conjugates with the in vitro ER-CALUX reporter gene assay. Environ. Toxicol. Chem. 21 (3) 473-479.

LIU JW and PICARD D (1998) Bioactive steroids as contaminants of the common carbon source galactose. FEMS Microbiol. Lett. 159 (2) $167-171$

McMAHON KD (2002) Microbial Ecology of Enhanced Biological Phosphorus Removal from Wastewater. Unpublished Doctoral Dissertation, University of California at Berkeley. $274 \mathrm{pp}$.

MERCK INDEX (1996) Vol. 2: An Encyclopedia of Chemicals, Drugs and Biologicals $\left(12^{\text {th }}\right.$ edn.). Merck \&Co., Inc., Whitehouse Station, NJ. 1498 pp.

MURK AJ, LEGLER J, VAN LIPZIG MMH, MEERMAN JHN, BELFROID AC, SPENKELINK A, VAN DER BURG B, RIJS GBJ and VETHAAK D (2002) Detection of estrogenic potency in wastewater and surface water with three in vitro bioassays. Environ. Toxicol. Chem. 21 (1) 16-23.

NG H-Y (2001) Personal communication - Activated sludge source and feed information. Currently at Division of Environmental Science and Engineering, National University of Singapore, Singapore.
ONDA K, NAKAMURA Y, TAKATOH C, MIYA A and KATSU Y (2003) The behavior of estrogenic substances in the biological treatment process of sewage. Water Sci. Technol. 47 (9) 109-116.

PAWLOWSKI S, TERNES T, BONERZ M, KLUCZKA T, VAN DER BURG B, NAU H, ERDINGER L and BRAUNBECK T (2003) Combined in situ and in vitro assessment of the estrogenic activity of sewage and surface water samples. Toxicol. Sci. 75 (1) 57-65.

PAWLOWSKI S, TERNES TA, BONERZ M, RASTALL AC, ERDINGER L and BRAUNBECK T (2004) Estrogenicity of solid phase-extracted water samples from two municipal sewage treatment plant effluents and river Rhine water using the yeast estrogen screen. Toxicol. in Vitro 18 (1) 129-138.

PICARD D (2001) Personal communication - Yeast construct RMY/ERERE and parent strain RMY326. Department of Cell Biology, University of Geneva, Switzerland.

RALOVICH B, IBRAHIM GAM, FÁBIÁN A and HERPAY M (1991) Beta-D-glucuronidase (BDG) activity of gram-negative bacteria. Acta Microbiol. Hung. 38 (3-4) 283-291.

ROUTLEDGE EJ and SUMPTER JP (1996) Estrogenic activity of surfactants and some of their degradation products assessed using a recombinant yeast screen. Environ. Toxicol. Chem. 15 (3) 241248 .

SCHERRER R, LOUDEN L and GERHARDT P (1974) Porosity of the yeast cell wall and membrane. J. Bacteriol. 118 (2) 534-540.

SERVOS MR, BENNIE DT, BURNISON BK, JURKOVIC A, MCINNIS R, NEHELI T, SCHNELL A, SETO P, SMYTH SA and TERNES TA (2005) Distribution of estrogens, 17beta-estradiol and estrone, in Canadian municipal wastewater treatment plants. Sci. Total Environ. 336 (1-3) 155-170.

STANDARD METHODS (1998) Standard Methods for the Examination of Water and Wastewater. APHA, AWWA, WEF. 2-57 - 59.

SVENSON A, ALLARD AS and EK M (2003) Removal of estrogenicity in Swedish municipal sewage treatment plants. Water Res. 37 (18) 4433-4443.

TABAK HH, BLOOMHUFF RN and BUNCH RL (1981) Steroid hormones as water pollutants II. Studies on the persistence and stability of natural urinary and synthetic ovulation-inhibiting hormones in untreated and treated wastewaters. Dev. Ind. Microbiol. 22 497-519.

TABAK HH and BUNCH RL (1970) Steroid hormones as water pollutants I. Metabolism of natural and synthetic ovulation-inhibiting hormones by microorganisms of activated sludge and primary settled sewage. Dev. Ind. Microbiol. 11 367-376.

TCHOBANOGLOUS G, BURTON FL and OTHERS (1991) Wastewater Engineering: Treatment, Disposal, and Reuse. McGraw-Hill, Inc. $1362 \mathrm{pp}$.

TERNES TA, KRECKEL P and MUELLER J (1999a) Behaviour and occurrence of estrogens in municipal sewage treatment plants - II. Aerobic batch experiments with activated sludge. Sci. Total Environ. 225 (1-2) 91-99.

TERNES TA, STUMPF M, MUELLER J, HABERER K, WILKEN RD and SERVOS M (1999b) Behavior and occurrence of estrogens in municipal sewage treatment plants - I. Investigations in Germany, Canada and Brazil. Sci. Total Environ. 225 81-90.

TILTON F, BENSON WH and SCHLENK D (2002) Evaluation of estrogenic activity from a municipal wastewater treatment plant with predominantly domestic input. Aquat. Toxicol. 61 (3-4) 211-224.

VANDERPERREN E, DEMARÉ W, BLUST R, COOREMAN K and BOSSIER P (2001) Oestrogenic activity of CPRG (chlorophenol red-b-D-galactopyranoside), a ß-galactosidase substrate commonly used in recombinant yeast oestrogenic assays. Biomarkers 6 (5) 375380 .

YU CP, AHUJA R, SAYLER G and CHU KH (2005) Quantitative molecular assay for fingerprinting microbial communities of wastewater and estrogen-degrading consortia. Appl. Environ. Microbiol. 71 (3) 1433-1444.

ZACHAREWSKI T (1997) In vitro bioassays for assessing estrogenic substances [Review]. Environ. Sci. Technol. 31 (3) 613-623. 